\section{Commentary: A ventricular assist device that does it all-in theory}

\author{
Ronald K. Woods, MD, PhD
}

The creative and innovative group from the Cleveland Clinic presents a new ventricular assist device for either the right or left ventricle. ${ }^{1}$ This pump incorporates a novel feature that permits a small degree of dynamic axial movement of the rotor. The pressure differential-responsive rotor movement permits (1) pulsatility; (2) functionality in either a lower pressure right ventricular or greater pressure left ventricular system; and (3) prevention of significant regurgitant volume with pump stoppage. I think most would agree that a single pump (albeit with different inflow cannulas) that provides good support to either the right or left ventricle is a distinct advantage. Despite the fact the very few patients wean to pump de-commission, there are apparent advantages of zero pump flow with minimal regurgitant volume when assessing native myocardial function. Whether blood stasis leads to thrombus formation and embolism remains to be seen, but this is an important theoretical concern. Leaving aside the debate regarding merits of pulsatile flow, let's just note that it might help and likely wouldn't hurt.

In a very acute calf model, Miyamoto and colleagues ${ }^{1}$ have demonstrated reasonable proof of concept. I suspect they have a plan to mitigate the negative cavity pressure, suck down, and overall relatively low pump flows for these large animals. Based on the images presented, further inflow cannula optimization seems in order in addition to

\footnotetext{
From the Division of Pediatric Cardiothoracic Surgery, Herma Heart Institute, Children's Wisconsin, Milwaukee, Wis; and Department of Surgery, Medical College of Wisconsin, Milwaukee, Wis.

Disclosures: The author reported no conflicts of interest.

The Journal policy requires editors and reviewers to disclose conflicts of interest and to decline handling or reviewing manuscripts for which they may have a conflict of interest. The editors and reviewers of this article have no conflicts of interest.

Received for publication June 3, 2020; revisions received June 3, 2020; accepted for publication June 10, 2020; available ahead of print July 8, 2020.

Address for reprints: Ronald K. Woods, MD, PhD, Department of Surgery, Medical College of Wisconsin, Division of Pediatric Cardiothoracic Surgery, Children's Wisconsin, 9000 W Wisconsin Ave, MS B 730, Milwaukee, WI 53226 (E-mail: rwoods@chw.org).

JTCVS Open 2020;3:149

2666-2736

Copyright (C) 2020 The Authors. Published by Elsevier Inc. on behalf of The American Association for Thoracic Surgery. This is an open access article under the CC BY-NCND license (http://creativecommons.org/licenses/by-nc-nd/4.0/).

https://doi.org/10.1016/j.xjon.2020.06.007
}

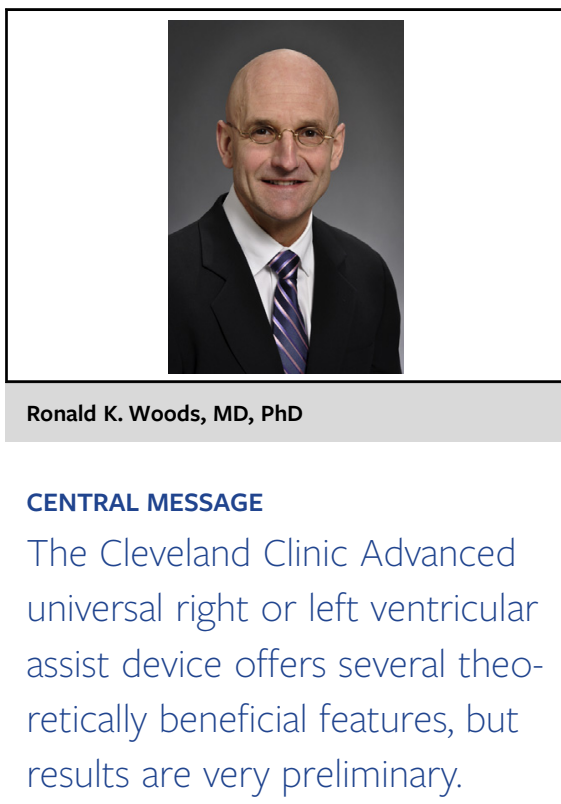

the intracardiac length of the cannula-currently there is notable distance between the pump head and the epicardial surface that occupies precious space if this pump is to be placed within the pericardium. In fact, the authors provide no test results with the sternum closed. Also, in contrast to testing in a normal heart, differential pressures in true failure model could also lead to relevant differences regarding the pump's capability to generate pulsatility. Nevertheless, the group in Cleveland has a strong record of productivity and progress. I encourage the authors and look forward to additional reports as they refine this pump and conduct longer-term testing.

\section{Reference}

1. Miyamoto T, Kado Y, Horvath DJ, Kuban BS, Sale S, Fukamachi K, et al. An advanced universal circulatory assist device for left and right ventricular support: first report of an acute in vivo implant. J Thorac Cardiovasc Surg Open. 2020;3: $140-8$. 